\title{
Е.С. Хованская
}

\section{ПРОЦЕСС ПРОБУЖДЕНИЯ ЭТНИЧЕСКОГО СОЗНАНИЯ И ОСО- БЕННОСТИ ХУДОЖЕСТВЕННОЙ СТРУКТУРЫ РОМАНА ДЖУЛИИ ОЦУКА «КОГДА ИМПЕРАТОР БЫЛ БОГОМ»}

\begin{abstract}
В статье исследуются формы проявления этнического сознания, особенности взаимодействия «своего» и «чужсого» в романе американо-японской писательниць Дж. Оиука «Когда император был богом» (2012). Выявляется специфика повествовательной стратегии, своеобразие развития двух разновекторных психологических сюжетов: второго рождения героев, обретших этническую идентичность, и её утраты, а также двух разнонаправленных мифологических сюжетов - моделирование «своего» мира и признание мифологизированного образа «чужого» как своего.

Ключевые слова: Дж. Оиука, этническое сознание, идентичность, повествовательная стратегия, субъективная реальность, психологический сюжет, мифологический сюжет.
\end{abstract}

Проблема этнического сознания человека, живущего в поликультурной среде, является сегодня одной из наиболее актуальных. Исследователи утверждают, что «современный период развития является временем своеобразного этнокультурного ренессанса» [1]. Различные аспекты данной проблематики рассматриваются этнологами, психологами, социологами, философами, культурологами, филологами (см.: [1-10]). Специалисты подчеркивают, что «"гены” (кровное родство) сами по себе не формируют ни этническое сознание, ни этническое самосознание. Оно определяется не биологическим фактором происхождения от родителей, относящихся к данному этносу, а социально-психологическим фактором - тем, что индивиды думают о своем происхождении» [4]. И то и другое проявляется «в виде осознания индивидом своей принадлежности к определенной этнической культуре, представлений об исторической судьбе, месте и роли этнонациональной группы в общей системе человечества» [8].

В научной литературе нет четкой дифференциации понятий «этническое сознание» и «этническое самосознание». Вслед за В.П. Левкович мы будем исходить из понимания этнического сознания как комплекса взглядов, идей, представлений, объективизирующихся в языке этнической группы, в системе народных обычаев и традиций, в преданиях, легендах, мифах, предполагающих наличие других этнических групп, отношение к ним данного этноса. Оно связано со способностью выделять себя (мы) из окружающих и противопоставлять себя им (они). Этническое самосознание, которое развивается в рамках этнического сознания, есть самоотражение этноса, его представление о себе как об особой реальности (см.: [5]). По мнению исследователей, в жизнедеятельности этнической группы этническое сознание и самосознание «выступают как целое, как одна из форм отражения 
этносом своего единства и отличия от других этнических общностей. Поэтому расчленение этнического сознания и самосознания возможно лишь в абстракции как методический прием, необходимый для более детального изучения» [5]. Нас преимущественно интересуют различные аспекты этнического сознания, но при необходимости мы также будем использовать термин «этническая идентичность» как синонимичный понятию «этническое самосознание».

В литературе США процессы этнического сознания и самосознания имеют свои особенности, связанные с тем, что американская нация является нацией иммигрантов. По свидетельству историков, с 1820 по 1987 г. в США приехало 54 миллиона человек разных национальностей. «На протяжении длительного периода в национальном развитии США явно преобладала интегрирующая тенденция, которая в начале XX века американскими специалистами была отражена в ассимиляционной парадигме "плавильный котел"» [11]. Однако интеграция не исключает периодического обострения этнических проблем. Так, во время Второй мировой войны после нападения японской армии на Пёрл Харбор все живущие в США японцы, в том числе и являвшиеся гражданами этой страны, были официально признаны врагами. Отчуждение части американской нации не могло не вызвать реакции, выраженной в конфронтационной формуле «мы - они». Враждебность со стороны национального большинства неизбежно способствовала активизации этнического сознания и самосознания японцев.

Предметом анализа в нашей работе являются формы выражения данного процесса в романе современной американо-японской писательницы Джулии Оцуки «Когда император был богом» (2012). Это единственное переведенное на русский язык произведение, посвященное проблеме интернирования японских американцев. Российская критика пока лишь краткими аннотациями на страницах некоторых изданий отметила факт открытия нового литературного имени и новой для российского читателя темы.

В интервью газете «Известия» Дж. Оцука призналась, что в основе книги - история семьи её матери, которая в феврале 1942 г. после объявления приказа Рузвельта №19, как и тысячи других людей японской национальности, была отправлена в концлагерь. Одновременно писательница заметила, что это и её «история тоже, правда, немного отстраненная. <..> первый роман всегда имеет дело с подавленными семейными чувствами» [12]. Дж. Оцука принадлежит третьему поколению японских иммигрантов, для которых английский язык и американская культура стали родными, они привыкли сознавать себя частью американской нации ${ }^{1}$. Возвращаясь к вопросу о том, что побудило её написать роман о лагере, писательница отметила: «...это история, которую нужно рассказать, тем более что это имело место здесь, в Америке, в то время, когда мы боремся за демократию и свободу за рубежом» [13]. Местоимение «мы» в этом высказывании подтверждает тот факт, что Дж. Оцука воспринимает себя частью

\footnotetext{
${ }^{1}$ По свидетельству специалистов, «современные нации - это, главным образом, “языковые нации”, состоящие из людей, говорящих на одном языке. Вместе с языковой “оболочкой” осваивается и её смысловая “начинка" - культурные традиции, принятые в культуре ценностные установки, идеалы, нормы мышления и поведения еtс.» [4].
} 
американского «мы». Тем не менее «подавленные семейные чувства», о которых она говорит, одновременно являются следствием осознания ею своей принадлежности к определенной этнической общности, что предполагает обособление от других этносов.

По наблюдению психолога А.А. Бучек, «в результате этнического самоопределения происходит поиск и определение личностью своего места и роли в мире, что $<\ldots>$ упорядочивает не только внешнюю реальность, но и субъективную реальность личности» [2]. Цель данной работы - выявить, как процесс этнического самоопределения и корректировки «субъективной реальности личности» проявляется в особенностях художественной структуры романа Дж. Оцука «Когда император был богом».

Ученые утверждают, что национальная идентичность коренится в архетипах мышления нации (см. в частности: [Молодяков В.Э., 1996 и др.]). Неудивительно, что название произведения Дж. Оцука, дающее ключ к его интерпретации, заостряет внимание на архетипических образах. Основной свод японских мифов «Кодзики» «утверждает статус императоров как прямых потомков богов - создателей Японских островов» [14. С. 31]. В композиции романа «Когда император был богом» воплощается идея космогонического мифа о крушении мира и о его новом воссоздании из хаоса. В структуре сюжета произведения выделяются несколько ключевых мотивов: прощания с жизнью, нисхождения в ад, воскрешения. Идея цикличности (жизни смерти - воскрешения) заложена и в названиях большинства глав, и в их последовательности: «Приказ об эвакуации № 19» (нарушение целостности мира, переход от жизни к смерти), «Поезд» (путь в мир мертвых), «Когда император был богом» (осознание этнической идентичности в кризисной ситуации), «Возвращение» (новый этап жизни).

Мифологический подтекст романа «Когда император был богом» неразрывно связан с психологическим сюжетом. Раскрытию внутренних процессов, происходящих в сознании героев, ищущих свое место в мире, подчинена и авторская повествовательная стратегия, которую отличает субъектная неоднородность. Хотя роман в основном написан от третьего лица, хотя стиль повествования кажется нейтральным, мировосприятие повествователя соотносится с мировосприятием четырех главных героев, каждый из которых выражает свое видение событий. В тексте помимо «повествовательного Я» выделяются несколько «повествуемых Я» (терминология В. Шмида), т.е. в каждой главе точка зрения нарратора дополняется позицией «другого»: вначале это точка зрения женщины, затем ее дочери, сына и в конце - ее мужа, который возвращается из другого лагеря для военных преступников. Кругозор каждого из них выражает индивидуальные ценностные ориентиры и одновременно демонстрирует различные формы репрезентации «японскости» и «американскости», их взаимодействие друг с другом. В целом такая повествовательная форма призвана показать изменения, которые происходят в «повествуемом» Я. Изменившиеся обстоятельства активизируют культурную и историческую память героев. Драматизм бытия, конфликт «своего» и «чужого» в сознании персонажей определяют внутренний диалогизм повествования. При этом содержание понятий «свой» и «чужой» у каждого из субъектов познания проявляется по-разному. Общим для всех героев является то, что 
они привыкли сознавать себя частью американского мира. Драматизм отношений возникает тогда, когда этот мир вдруг отторгает их. Вынужденная маргинальность положения способствует пробуждению этнического самосознания героев.

Закономерно, что в первой главе повествование передает точку зрения матери, поскольку она является хранительницей дома, с ней связано представление о целостности мира. Но именно женщина читает приказ №19, следуя которому ей предстоит разорить собственный дом.

Вначале, когда целостность привычного бытия еще сохраняется, точка зрения героини проявляется с помощью ряда деталей, акцентирующих внимание на ее феминности и социальном статусе. Отправляясь за покупками, она надела белые шелковые перчатки и красное платье, которое, как заметил владелец магазина Джой Лайди, ей очень шло. Маршрут ее движения свидетельствует о том, что эта японская семья живет в центре города, их социальное положение прочно, они не чувствуют себя маргиналами. Но недаром в числе деталей, характеризующих внешний облик героини, выделяются её новые очки. В данном контексте они воспринимаются как знак нового видения. Внезапно наводнившие город листовки с приказом №19 обозначают конец прежней жизни. Неудивительно, что с этого момента изменяется восприятие героиней всего происходящего. Уже в сцене разговора с владельцем хозяйственного магазина обращает на себя внимание характерная психологическая подробность: женщина впервые назвала Джойя Ланди по имени. До этого «такая фамильярность казалась ей странной. Даже неприличной» [15. С. 154]. Тем не менее эта сцена свидетельствует, что вначале граница между «мы» и «они» размыта, конфронтация отсутствует.

Основное действие начинается в тот момент, когда из-за враждебности американского окружения конфликт обостряется. После того как был арестован глава семейства, «мать развела в саду костер и сожгла все письма из Кагосимы. Семейные фотографии и три шелковых кимоно, которые девятнадцать лет назад привезла из Японии. Пластинки с записями японских опер. Разорвала на клочки флаг с восходящим солнцем. Разбила вдребезги чайный сервиз, тарелки имари и вставленный в рамку портрет дяди мальчика, который когда-то был генералом армии императора. Расколола старинные счеты и бросила в костер» [15. С. 217]. Обратим внимание на знаки препинания в приведенном фрагменте: автор использует точки там, где, кажется, могли бы быть запятые, фиксирующие последовательность однородных действий. Как утверждает языковед П.Я. Черных, слово «запятая» - это результат субстантивации глагола «запятися», что означает «зацепиться, задеть» [16. С. 341], т.е. это связующий знак, а героиня Дж. Оцука переживает драму разрыва связей. Точка помогает сделать тонкие смысловые выделения, она несет эмоционально-оценочную функцию, призвана передать ту боль, которую испытывает героиня, когда ей приходится разорвать все связи с национальным миром и фактически остаться без лица. Точки, подобно нотным знакам, передают внутренний ритм. Обозначаемая ими продолжительность пауз между действиями отражает психологическую напряженность состояния героини и одновременно создает визуальный 
рисунок этих действий. Эмоциональные паузы предполагают психологический подтекст: за каждой уничтоженной вещью - память, индивидуальная, семейная, национальная. Героиня чрезвычайно сдержанна в выражении своих чувств, её точка зрения выражена только с помощью характерного синтаксиса и лексики. Каждая фраза содержит эмоционально окрашенные глаголы и наречия: «разорвала на клочки», «разбила вдребезги», «расколола», «бросила в костер».

Примечательно, что уже «на следующий день, отправляя детей в школу, мать впервые положила в их коробки для завтрака сэндвичи с джемом и арахисовым маслом. «Больше никаких роллов», - сказала она. - А если кто поинтересуется вашей национальностью, отвечайте, что вы китайцы» [15. C. 218].

Приказ №19 вынуждает японцев покинуть свои дома. Интернирование в сознании героини ассоциативно связано со смертью. Это позволяет все ее действия интерпретировать как подготовку к ней. В частности, убийство домашнего любимца - старого Белого Пса воспринимается как своеобразное жертвоприношение, но в особой трансформированной форме. Семья лишается защиты и надежды и отправляется в неизвестность без проводника. Осознание рубежности происходящего выражается и через ряд вещных деталей: собираясь в дорогу, мать отложила в сторону вещи, воспринимающиеся в данном контексте как знаки американской культуры фигурку индейца, бейсбольную перчатку, комиксы и книги об американских птицах.

Путь в лагерь представлен в романе как путь в мир мертвых. Об этом свидетельствует характерная символика: одиноко круживший над поездом черный ворон, черные лошади, как бы сопровождающие его. Характерно и само расположение лагеря - на дне высохшего соляного озера, что рождает ассоциацию с адом ${ }^{1}$.

Во второй главе происходящее представлено глазами девочки, которая провела «в Калифорнии все свою неполную жизнь» [15. С. 171]. Она не знает родного языка, в поезде, который везет их в лагерь, девочка читает журнал «Нэшнлджиографик»... Когда к ней с каким-то вопросом обращается пожилой японец, девочка не понимает его. В его ответной реплике «Вот, значит, как!» выражено не просто осознание границы, разделяющей два мира - японский и американский, но и осознание произошедшего разрыва связи между поколениями внутри японского мира. На данном этапе процесс осознания происходящего - прерогатива взрослых. Дети принадлежат поликультурному американскому миру. Когда после ареста отца мать приказала им называть себя китайцами, девочка ответила:

- А я королева Испании [15. С. 218].

Дети готовы надеть на себя любую чужую «маску», даже если к представителям этой национальности они относятся с презрением. Так, еще до отправки в лагерь какой-то парень остановил мальчика на улице и спросил: «Ты китаеза или япошка?»- И он ответил «Китаеза» [15. С. 219].

\footnotetext{
${ }^{1}$ О символическом подтексте романа см. подробнее в нашей статье «Мифологический подтекст в романе Дж. Оцуки «Когда император был богом» [17].
} 
О том, что дети не задумываются о своем японском происхождении, свидетельствует и то, что мальчик, мечтая о возвращении отца, представлял его в обличии ковбоя, «в <..> сапогах и шляпе», гарцующим «на красивом жеребце по имени Белый Иней» [15. С. 225]. Детей удивляет, что в поезде, а затем и в лагере их окружают только желтые лица с раскосыми глазами. Это вновь подтверждает, что сами они пока не соотносят себя со своим этносом. Примечательно, что, играя в лагере в войну, они кричат: «Смерть нацистам!» и «Смерть япошкам!» [15. С. 197].

По справедливому утверждению А.А. Бучек, этническое самосознание является результатом индивидуального опыта личности, предполагающего «не пассивное усвоение некоторых норм и требований определенного этноса, а творческое преобразование внутри личности» [2]. В лагере для японских американцев начинается новая жизнь, что объясняет актуализацию мифологического мотива инициации, прохождения через испытания. «Преобразование внутри личности» сопровождается обретением новых социальных ролей. Так, «человек, который драил в столовой кастрюли и сковородки, прежде был менеджером по продажам в одной из импортноэкспортных компаний Сан-Франциско. Уборщице прежде принадлежал небольшой детский сад» [15. С. 199].

Оторванность от привычной жизни, вынужденная замкнутость существования в исключительно японской среде неизбежно пробуждают потребность в осознании героями своей этнической идентичности. Для детей это обретение нового знания о своем - японском - мире, для взрослых реконструкция культурной и исторической памяти. Главная героиня вспоминает время, проведенное в родительском доме, воображает себя маленькой девочкой. И только тогда ее взгляд оживляется, на лице появляется улыбка, которую дети давно не видели. Она рассказывает им о Японии, ее традициях, восстанавливая таким образом связь поколений.

В главе, организованной точкой зрения мальчика, особенно наглядно проявляется связь внутренних преобразований с начальным опытом мифотворчества. Герой ощущает себя как бы вне времени, ему кажется, что за пределами проволочной изгороди «всегда шесть часов вечера. Может вечера среды, а, может, четверга. И люди там всегда собираются обедать» [15. С. 209]. Реминисценция к произведению Л. Кэррола «Алиса в стране чудес»след культурной памяти, обозначающий связь с покинутым американским миром, но одновременно через «чужое слово» обнаруживает себя и японская культурная прапамять, сохранившаяся на подсознательном уровне. Таким образом, настоящее становится звеном накопленных культурных смыслов.

Мальчик, не знающий японского языка, как заклинание, повторяет имя императора, хотя в лагере оно было под запретом. Это имя «слетало с его губ само собой» [15. С. 196]. Он видит императора и в своих снах. Вместо окружающей лагерь пустыни ему представляется море. «А у самого горизонта виднеются силуэты трех кораблей. <..> Сам император прислал их за мальчиком» [15. С. 196]. Ему также часто снилась красивая деревянная дверь. «Это была очень маленькая дверь - размером с подушку или с том энциклопедии. За этой маленькой красивой дверью была другая дверь, а за ней портрет императора, на который не дозволялось смотреть никому. 
Потому что особа императора была священной. Потому что он был богом» [15. С. 216].

Так проясняется смысл названия романа «Когда император был богом»восстановление утраченных связей, приобщение к опыту этноса. Процесс осознания своего бытия в мире, сопровождающийся накоплением этнического опыта, продолжается и после возвращения героев из лагеря. Им предстояло заново восстанавливать и обживать покинутый дом, который обретает для них новую ценность. Символична находка фигурки Будды, которую мать обнаруживает, когда приводит в порядок сад. Они «счистили грязь с его толстого живота и огромной круглой головы и увидели, что он по-прежнему смеется» [15. С. 265]. Смеющийся Будда - один из семи японских богов счастья, богатства, веселья и благополучия (см.: [14]).

И все же время, проведенное в лагере, наложило на героев свой отпечаток. Характерно, что первую ночь они провели в той комнате своего дома, которая больше всего напоминала их лагерную каморку - длинную и узкую. И разместились в ней так, как спали в бараке. При этом они легли спать в своей лучшей одежде. «Нельзя, чтобы нас убили в пижамах», пояснила мать. В этой реплике выражена характерная особенность психологии японцев - enryo - представление о том, как вести себя в неловких ситуациях, чтобы избежать позора и соблюсти «лицо» [18. С. 124]. Здесь эта ситуация усугубляется конфронтацией «они»/«мы». Находясь в лагере, дети мечтали, что после возвращения в родной город «телефон будет разрываться от звонков. ("Наконец-то вы вернулись! Мы вас так ждали!" $<. .>$ "Какое счастье, что вы снова с нами! Нам вас так не хватало!”)» [15. С. 266]. В реальности им пришлось столкнуться с комплексами массового сознания, порожденными этноцентризмом, когда все чужое воспринимается как опасное. Подобно тому, как при интернировании японцев никто из их американских соседей не вышел попрощаться с ними, так и после их возвращения в город «они делали вид, что не замечают» японцев и отворачивались от них при встрече. Мать объяснила такое поведение соседей страхом перед «чужими», ставшими врагами.

Встреча с враждебностью приводит к тому, что и сами японцы вынуждены принять навязанную им роль. Дети вновь, как это было, когда они только оказались в лагере, пугаются «своего лица». Чужой страх порождает свой, новый. Вместе с тем после всего пережитого в их самооценке и мировосприятии происходят существенные изменения:

«Мы смотрели на себя в зеркало, и то, что мы там видели, нам очень не нравилось: черные волосы, желтая кожа, раскосые глаза. Отвратительные лица врагов.

Мы чувствовали свою вину. Но ведь мы совершенно ни при чем. И все же мы японцы. Не надо об этом думать. Мы представители вражеской нации. Теперь мы свободны. Никто нас ни в чем не обвиняет. Нам никогда не будут доверять. И с этим ничего нельзя сделать» [15. С. 260].

В этом внутреннем монологе проявляется внутренняя борьба двух Я, происходящая в сознании героев. С одной стороны, на них оказывают влияние стереотипы массового сознания, заставляющие их видеть не свое отражение, а «отвратительное лицо врага», испытывать «чувство вины», 
вызванное принадлежностью к «вражеской нации». Для детей по-прежнему важно сознавать себя органической частью американского социума, они готовы не только говорить, но и мыслить на его «языке». Выпадение из мира, который прежде они воспринимали как «свой», переживается ими болезненно. С другой стороны, в пользу обретения этнической идентичности свидетельствует признание того, что они «японцы», что они «совершенно ни при чем» и что они «свободны».

Постепенно «жизнь вошла в прежнюю колею», откровенная враждебность со стороны национального большинства, казалось бы, исчезла. Если вначале после возвращения в свой дом герои запирали не только двери, но и окна и «ждали, когда тишину разорвет выстрел или стук в дверь», то через год они уже спали с открытыми окнами. Но обоюдная подозрительность осталась. Об этом, в частности, свидетельствует микросюжет об исчезнувшем из сада за время отсутствия героев кусте роз. Дети искали его повсюду. Им казалось, что они видят его перед домом каждого из соседей. Но даже когда это не подтверждалось, они «всегда верили, что где-то, в саду позади чужого дома, красуется <..> куст, сплошь усыпанный чудесными красными розами» [15. С. 278].

Недоверие друг к другу заставило обе стороны выработать свои «средства защиты». И американцы и японцы старались соблюдать правила приличия и делать вид, что ничего не произошло. Японцам еще перед освобождением из лагеря была прочитана специальная лекция «Как вести себя после возвращения»: «Разговаривать только по-английски. Не собирайтесь на улице больше чем по трое. <..> Старайтесь не привлекать к себе внимания» $[15$. C. 262].

Установка не привлекать к себе внимание не только соответствовала конкретной политической ситуации, требовавшей от японцев стать как бы невидимыми для американцев, но и выражала характерную черту японской ментальности, определяющую их поведение вне этой ситуации, «эмоциональная закрытость», или gaman, - подчеркнутая сдержанность в проявлении чувств, эмоций, способность скрывать свой внутренний мир под непроницаемой маской вежливости [18. С. 125].

Последнее объясняет значимость в структуре сюжета романа мотива маски, связанного с оппозицией «своё»/«чужоё». Но этот мотив по отношению к разным героям романа проявляет себя по-разному. Для вернувшихся из лагеря женщины и её детей это вынужденное, но вполне осознанное поведение: им пришлось надеть «маску», чтобы сохранить лицо. Отец семейства, напротив, пройдя через испытания, пережил трагедию утраты своего Я. В заключительной главе с характерным названием «Признание» он принимает точку зрения американцев, видящих в японцах врагов. Заключительная глава строится в форме я-повествования, но личное местоимение «я» в данном случае выражает коллективное «мы». Причем это мы в данном случае - знак обезличенности. Речь героя состоит из гетеростереотипов, выражающих представление об этнопсихологическом облике другого народа и имеющих резко негативный характер:

«Будь по-вашему, сказал я. Запираться бесполезно. Я во всём признаюсь. Вы совершенно правы. Вы всегда правы. Все это сделал я. Я отравлял ваши 
резервуары с питьевой водой. <..> Я сообщал врагу, где расположены ваши аэродромы. <...> Шпионил за соседями. Шпионил за вами ...» [10. С. 279].

Заключительная глава представляет длинный перечень всех «преступлений», которые герой якобы совершил против американского народа. Замещение своего Я чужим выражается в акте высказывания, в котором уже не остается места для субъективного начала, говорящего - все замещается голосом враждебного массового сознания:

«Я косоглазый снайпер, сидящий на дереве в вашем саду. Я диверсант, притаившийся в зарослях. Я чужестранец, бродящий у ваших ворот. Я предатель, проникший в ваш дом. Я ваш слуга. Я ваш повар. Я ваш садовник. Я тихо жил здесь, рядом с вами, и в течение многих лет терпеливо ждал, когда Тоджо 17 подаст мне сигнал к действию. <..> Вот и все. Больше мне нечего сообщить. Теперь я могу идти?» [10. С. 282].

«Ложное слово» героя становится свидетельством его духовного опустошения, омертвения. Даже после освобождения из лагеря он не смог вернуться в мир живых. Это замечают даже дети:

«Наш отец, тот отец, которого мы помнили, отец, которого мы видели во сне почти каждую ночь, был красивым и сильным. Он высоко держал голову, двигался быстро и уверенно. Любил рисовать. Петь. Смеяться» [10. С. 272].

Человек, который теперь был рядом с ними, был совершенно другим. Это подчеркивается цепочкой отрицательных конструкций:

«Он не рисовал и не пел. <..> Он не читал нам вслух. <..> Не устраивал на стене представлений театра теней, переплетая пальцы самым причудливым образом. Он не клеил нам змеев и не делал ходулей. <..> Он ничего не рассказал нам о том, как провел все эти годы» [10. С. 272].

Когда дети, вернувшись из школы, рассказывали, по его же просьбе, что «новенького» у них произошло, он делал вид, что внимательно их слушает, но «думал о чём-то другом». Вечером он укладывался спать рано и «часто видел один и тот же сон: прошло уже пять минут после комендантского часа, а он еще не вернулся за проволочную изгородь. <..> Всякий раз он просыпался с криком:

- Я опоздал!» [10. С. 277].

Таким образом, в романе Джулии Оцука «Когда император был богом» прослеживаются два разновекторных психологических сюжета. В одном из них, связанном с судьбами матери и детей, автор акцентирует внимание на возрождении и одновременно на втором рождении героев в результате пробуждения этнического самосознания, тогда как в сюжетной линии отца, напротив, акцентируется трагедия обезличивания как результат поглощения «своего» «чужим». Принимая «чужое слово» как свое, герой лишается самостоятельности, совершается подмена собственного восприятия «слышимым», индивидуального - массовым. Этому сопутствуют и два разнонаправленных мифологических сюжета: первый связан с моделированием «своего» мира, второй - с признанием мифологизированного образа «чужого» как своего. 


\section{Лuтература}

1. Костина А.В. Национальная и этническая культура: соотношение в глобализирующемся мире // Знание. Понимание. Умение. 2006. №3. С. 128-139.

2. Бреева Т.Н., Хабибуллина Л.Ф. Национальный миф в русской и английской литературе. Казань: ТГГПУ, 2009. $611 \mathrm{c.}$

3. Бучек A.A. Психологические закономерности функционирования этнического самосознания в полиэтнической среде: автореф. дис. ... д-ра психол. наук. Петропавловск-Камчатский. 2012. $52 \mathrm{c}$.

4. Гожева О.К. Философско-этнологическая рефлексия феномена этнонационального сознания // Научные проблемы гуманитарных исследований. 2009. №14. С. 99-104.

5. Левкович В.П. Социально-психологические аспекты этнического сознания // Сов. этнография. 1983. № 4. С. 75-79.

6. Петрова К.А. Этническое самосознание как психологический феномен // Омский научный вестник. 2008. №5(72). С. 146-149.

7. Попова М.К. Национальная идентичность и её отражение в художественном сознании. Воронеж: Воронеж. гос. ун-т, 2004. 170 c.

8. Тоидис В.П. Этнонациональное самосознание как феномен культуры. Карачаевск, 1999. C. $32-33$.

9. Guciykunst W.B., Ting-Toomey S., Chua E. Culture and interpersonal communication. SAGE Publications, Inc., 1988. 280 p.

10. Kim Y.Y. Communication and cross-cultural adaptation. Multilingual Matters, 1988. 223 p.

11. Черчина 3.С. Этничность в США: теория «плавильный котёл» // Американский ежегодник. 1994. Т. 1993. С. 151-161.

12. Джулия Оиука: «Японцы стараются держать свои проблемы при себе» // Известия. 2014. 28 февр. // http://izvestia.ru/news/566625 (проверено: 12.10.2015).

13. A Conversation with Julie Otsuka, author of When the Emperor was Divine // https://www.bookbrowse.com/author_interviews/full/index.cfm/author_number/807/julie-otsuka (проверено: 12.10.2015).

14. Садокова A.P. Японский фольклор: (В контексте мифолого-религиозных представлений). М.: ИМЛИ РАН, 2001. 256 с.

15. Оиука Д. Когда император был богом. СПб.: ООО «Издательская группа “АзбукаАттикус"». 2013. С. 151-283.

16. Черных П.Я. Историко-этимологический словарь современного русского языка: в 2 т. Т. 1. 3-е изд., стер. М.: Рус. яз., 1999. 623 с.

17. Хованская Е.С. «Мифологический подтекст в романе Дж. Оцуки «Когда император был богом» // Филология и культура. 2015. № 3. С. 270-273. $231 \mathrm{p}$.

18. Harry H.L. Kitano Japanese Americans: The evolution of a Subculture. Prentice Hall, 1989.

\section{THE AWAKENING OF ETHNIC CONSCIOUSNESS AND FEATURES OF THE ARTISTIC STRUCTURE OF JULIE OTSUKA'S WHEN THE EMPEROR WAS DIVINE}

Tomsk State University Journal of Philology, 2016, 1(39), pp. 160-171.

DOI: $10.17223 / 19986645 / 39 / 14$

Khovanskaya Ekaterina S., Kazan Federal (Volga Region) University (Kazan, Russian Federation). E-mail: katja.khovanskaya@gmail.com

Keywords: Julie Otsuka, ethnic consciousness, identity, narrative strategy, subjective reality, psychological plot, mythological plot.

The paper deals with ethnic consciousness manifestations as well with characteristic features of "self" and "non-self" in Julie Otsuka's novel When the Emperor Was Divine (2012). The ethnic consciousness of a person living in a multinational environment is a relevant issue. The author determines the term "ethnic consciousness" as a scope of beliefs, ideas and concepts which manifest themselves in the language of the ethnic group, in its customs and traditions as well as in the legends, myths.

The aim of the paper is to see how the artistic structure of the novel reflects the process of ethnic identification and adjusting of the subjective reality of a person. Julie Otsuka belongs to the third generation of Japanese immigrants who got used to identifying themselves as belonging to the American 
nation. In the novel, Julie Otsuka tells the story of her mother thus trying to realize that she belongs to the Japanese ethnic community. However, this fact implies that she has to oppose herself to the other ethnic groups.

The title helps to analyze the novel putting forward the archetypical characters which give rise to the archetypical mentality of the nation. The paper shows that the plot of the novel When the Emperor Was Divine is based on the cosmogonical myths about the doomsday which is followed by the rebirth of the world from chaos. The mythological motives: farewell to life, descent to hell, resurrection, are developed in the structure of the novel. The author reveals the cyclic nature of the events. The idea of the cycle (life - death - rebirth) is reflected in the chapter titles. The paper shows that the mythological code of the novel is closely connected with its psychological plot.

The narrative strategy of the novel reveals the processes going on in the characters' minds. The author proves that in the text there is a "narrative I" as well as some kinds of a "narrated I". Each chapter has a narrator's point of view which combines the attitude of "another": the point of view of the woman, then her daughter's, her son's and, finally, her husband's, who returns from an internment prison. The author demonstrates that the mentality of each character, their individual values combine both Japanese and American features in their interaction. This narrative form is used to show all the changes that are developing in the "narrated I".

The paper focuses on two major psychological plot lines of the novel. One of them, connected with the story of mother and her children, emphasizes the moment of the rebirth of the characters. The rebirth resulted from the awakening of the ethnic identification. The other one, connected with the story of father, puts forward the tragedy of depersonalization due to the loss of identity. The psychological lines are paralleled by two corresponding myths. The first describes the creation of the "self" world while the other one presents the acceptance of the "non-self" mentality.

\section{References}

1. Kostina, A.V. (2006) Natsional'naya i etnicheskaya kul'tura: sootnoshenie v globaliziruyushchemsya mire [National and ethnic culture: the ratio in the globalized world]. Znanie. Ponimanie. Umenie. 3. pp. 128-139.

2. Breeva, T.N. \& Khabibullina, L.F. (2009) Natsional'nyy mif v russkoy i angliyskoy literature [National Myth in Russian and English literature]. Kazan: TGGPU.

3. Buchek, A.A. (2012) Psikhologicheskie zakonomernosti funktsionirovaniya etnicheskogo samosoznaniya $v$ polietnicheskoy srede [Psychological patterns of ethnic identity functioning in a multiethnic environment]. Abstract of Psychology Dr. Diss. Petropavlovsk-Kamchatsky .

4. Gozheva, O.K. (2009) Filosofsko-etnologicheskaya refleksiya fenomena etnonatsional'nogo soznaniya [Philosophical and ethnological reflection of ethno-national consciousness phenomenon]. Nauchnye problemy gumanitarnykh issledovaniy. 14. pp. 99-104.

5. Levkovich, V.P. (1983) Sotsial'no-psikhologicheskie aspekty etnicheskogo soznaniya [Sociopsychological aspects of ethnic consciousness]. Sovetskaya etnografiya. 4. pp. 75-79.

6. Petrova, K.A. (2008) Etnicheskoe samosoznanie kak psikhologicheskiy fenomen [Ethnic selfconsciousness as a psychological phenomenon]. Omskiy nauchnyy vestnik. 5(72). - pp. 146-149.

7. Popova, M.K. (2004) Natsional'naya identichnost' $i$ ee otrazhenie $v$ khudozhestvennom soznanii [National identity and its reflection in the artistic consciousness]. Voronezh: Voronezh State University.

8. Toidis, V.P. (1999) Etnonatsional'noe samosoznanie kak fenomen kul'tury [Ethno-national identity as a cultural phenomenon]. Karachaevsk: Karachay-Cherkess State Pedagogical University.

9. Guciykunst, W.B., Ting-Toomey, S. \& Chua, E. (1988) Culture and interpersonal communication. SAGE Publications, Inc.

10. Kim, Y.Y. (1988) Communication and cross-cultural adaptation. Multilingual Matters.

11. Cherchina, Z.S. (1994) Etnichnost' v SShA: teoriya "plavil'nyy kotel" [Ethnicity in the United States: the theory of "melting pot"]. Amerikanskiy ezhegodnik. 1993. pp. 151-161.

12. Otsuka, J. (2014) "Yapontsy starayutsya derzhat' svoi problemy pri sebe" ["The Japanese are trying to keep their problems to themselves"]. Izvestiya. 28 February. [Online]. Available from: http://izvestia.ru/news/566625. (Accessed: 12 October 2015).

13. BookBrowse. (n.d.) A Conversation with Julie Otsuka, author of When the Emperor was Divine. [Online]. Available from: https://www.bookbrowse.com/ author_interviews/ full/index.cfm/ author_number/807/julie-otsuka. (Accessed: 12 October 2015). 
14. Sadokova, A.R. (2001) Yaponskiy fol'klor (V kontekste mifologo-religioznykh predstavleniy) [apanese folklore (in the context of the mythological and religious ideas)]. Moscow: Institute of World Literature, RAS.

15. Otsuka, J. (2013) Kogda imperator byl bogom [When the Emperor was Divine]. Translated from English. St. Petersburg: Azbuka-Attikus.

16. Chernykh, P.Ya. (1999) Istoriko-etimologicheskiy slovar' sovremennogo russkogo yazyka: v 2 tomakh [Historical and etymological dictionary of modern Russian language: in 2 vols]. 3rd ed. Vol. 1. Moscow: Russkiy yazyk.

17. Khovanskaya, E.S. (2015) Implicit Mythology of J. Otsuka's Novel When the Emperor was Divine. Filologiya i kul 'tura - Philology and Culture. 3. pp. 270-273. (In Russian).

18. Kitano, H.H.L. (1989) Japanese Americans. The evolution of a Subculture. Prentice Hall. 